Sintese - Rev. de Filosofia

v. 28 N. 90 (2001): $67-96$

\title{
ANÁLISE ARGUMENTATIVA DO TEXTO "ON DENOTING" DE B. RUSSELL [MIND, V. 14 (1905), PP. 479-93]
}

Paulo R. Margutti Pinto UFMG

Resumo: 0 famoso texto de Russell é analisado como uma peça argumentativa. 0 método de análise especialmente projetado para tal tarefa envolve três passos: i) consideração do contexto da obra; ii) exposição da abordagem proposta pela obra; iii) consideração das técnicas argumentativas adotadas pelo autor. 0 método já foi aplicado com sucesso na análise de dois textos bastante heterodoxos, a saber, A origem da tragédia, de $\mathrm{N}$ ietzsche, e o Tractatus, de Wittgenstein. 0 método está sendo aplicado no presente trabalho a um texto logicamente ortodoxo, para verificar seu potencial neste novo domínio. os resultados mostram impressionantemente que, embora lidando com assuntos lógicos, a argumentação de Russell tem muitas falhas que foram escondidas através do apelo a técnicas retóricas, tais como descritas por Perelman \& Olbrechts-Tyteka em Traité de l'Argumentation.

Palavras-chave: Russell, Descrições definidas, A rgumentação, Retórica.

Abstract: Russell's famous text is analyzed as an argumentative piece. The method of analysis specially designed for such a task involves three steps: i) consideration of the context of the work; ii) exposition of the approach proposed by the work; iii) consideration of the argumentative techniques adopted by the Author. The method has already been successfully applied in the analysis of two very unorthodox texts, namely Nietzsche's The 0 rigin of Tragedy and Wittgenstein's Tractatus. The method is now applied to a logically orthodox text in order check its capabilities in this new domain. The results strikingly 
show that, although dealing with logical matters, Russell's argumentation has many flaws, which have been concealed by appealing to rethorical techniques such as described by Perelman \& Olbrechts-Tyteka in their Traité de l'Argumentation.

Key words: Russell, Definite descriptions, Argumentation, Rhetoric.

\section{I - Observações preliminares}

Nos últimos anos, concentramos o foco de nossa pesquisa na questão da argumentação filosófica. Isto nos permitiu desenvolver um método específico de análise do texto filosófico, que parte do princípio de que o mesmo é, antes de tudo, uma peça argumentativa.

Nesta perspectiva, a análise de um texto passa, em geral, por três momentos diferentes. $O$ primeiro deles considera o contexto no qual a obra se insere. Por 'contexto' entendemos aqui o conjunto de todos os fatos, idéias e procedimentos relevantes para a compreensão do ambiente cultural que gera o problema a que o texto analisado procura responder. Isto fornece o ponto de partida da argumentação desenvolvida pelo texto analisado. O segundo momento consiste na exposição da solução encontrada pelo autor. Isto envolve a elaboração de uma conjetura interpretativa que está sujeita aos mesmos problemas de qualquer exegese. $O$ terceiro momento consiste na análise das técnicas argumentativas utilizadas pelo texto. Esta análise envolve a consideração dos seguintes aspectos fundamentais da argumentação no texto analisado: a estratégia geral de argumentação, os esquemas argumentativos utilizados, os procedimentos heurísticos e a avaliação da convergência dos argumentos. Embora cada momento envolva uma conjetura específica, a comparação entrecruzada dos resultados obtidos em cada um deles permite o reforço ou a modificação de uma conjetura a partir da outra, produzindo uma interpretação mais fundamentada do texto como um todo. A vantagem do método está em que, ao enfocar o texto como peça argumentativa, somos levados a considerar, na interpretação do mesmo, todos os fatores que intervêm na sua composição: o próprio texto, as intenções do autor, o contexto e o público a que se destina ${ }^{1}$.

\footnotetext{
${ }_{1}$ Para maiores esclarecimentos com respeito a este método, ver P. R. MARGUTTI, Iniciação ao Silêncio. Uma análise do Tractatus de Wittgenstein, São Paulo: Loyola, 1998, 15-35. Alternativamente, ver IDEM, Análise do discurso e argumentação, in: H. MARI ET ALII (eds.), Fundamentos e dimensões da análise do discurso, B. Horizonte: Núcleo de Análise do Discurso (FALE/UFMG), Carol Borges Editora, 1999, 87-106.
} 
O método descrito acima já foi aplicado de maneira sistemática em pelo menos dois casos. No primeiro, fizemos a análise argumentativa de $\mathrm{A}$ origem da tragédia, de N ietzsche ${ }^{2}$. No segundo, aplicamos o mesmo tipo de análise ao Tractatus, de Wittgenstein ${ }^{3}$. Em ambos, o método revelouse eficaz não só para compreender, mas também para explicar a especificidade de tais textos, geralmente considerados al heios aos padrões argumentativos tradicionais.

O objetivo do presente trabal ho é ilustrar a aplicabilidade do método também a casos mais ligados à argumentação tradicional, de tipo socrático. N este processo argumentativo, que se opõe tanto ao utilizado por Nietzsche em A origem da tragédia quanto ao utilizado por Wittgenstein no Tractatus, cada afirmativa feita pelo autor deve ser criteriosamente justificada por uma ou mais razões, com base em inferências lógicas estabelecidas pela racionalidade comum ao gênero humano. Para realizar esta tarefa, escolhemos o texto $0 \mathrm{n}$ D enoting, em que $B$. Russell expõe e defende, com argumentos predominantemente lógicos, a famosa Teoria das D escrições. Isto permitirá a aplicação do método a um texto cujo tipo de argumentação é, inegavel mente, socrático ${ }^{4}$.

As etapas envolvidas pela realização da análise serão as seguintes. Primeiramente, analisaremos o contexto de $0 \mathrm{n}$ D enoting, mostrando não apenas a atmosfera intelectual à época da redação do artigo, mas também a própria evolução de Russell em direção à sua teoria. Isto nos fornecerá o ponto de partida da argumentação russelliana. Em segundo lugar, faremos a apresentação da Teoria das Descrições tal como a entendemos, indicando inclusive os princípios dos quais ela é obtida e as conseqüências por ela produzidas. Em terceiro, analisaremos os principais aspectos argumentativos de $0 \mathrm{n}$ D enoting, envolvendo a estratégia geral de argumentação adotada por Russell, os esquemas argumentativos utilizados, as técnicas heurísticas adotadas e a convergência dos argumentos. Em quarto e último lugar, tentaremos extrair algumas conclusões com base no percurso feito. A expectativa é que teremos condições de mostrar que o método pode ser também aplicado a argumentações de caráter técnico e que, mesmo em tais casos, a ligação do texto com sua época e com técnicas argumentativas semeIhantes àquelas estudadas por Perelman e Olbrechts-Tyteca em sua $\mathrm{N}$ ova retórica deve ser levada em conta.

\footnotetext{
${ }^{2}$ Ver P. R. MARGUtTI, Nietzsche, a Filosofia e a Retórica: uma análise de A Origem da Tragédia enquanto forma de argumentação, Kriterion, Revista de Filosofia, vol. XXXV, no 89 (janeiro a julho/1994) 45-73.

3 Ver P. R. MARgutti, Iniciação ao Silêncio. Uma análise do Tractatus de Wittgenstein, São Paulo: Loyola, 1998.

4 Para maiores esclarecimentos com respeito à noção de argumentação socrática, ver a seção IV de P. R. MARGUTTI, Nietzsche, a Filosofia e a Retórica: uma análise de $A$ Origem da Tragédia enquanto forma de argumentação, Kriterion, Revista de Filosofia, Vol. XXXV, oo 89 (janeiro a julho/1994) 60-71.
} 


\section{O contexto e o ponto de partida de "On denoting" 5}

Uma das características mais marcantes de Russell está na evolução de seu pensamento em direção à busca constante de soluções lógicas para questões metafísicas. Nesta perspectiva, o que move a filosofia russelliana é o desejo ockhamiano de reduzir ao máximo o número de entidades utilizadas na explicação da realidade. No início de sua carreira, contudo, Russell é influenciado pelas doutrinas idealistas de Kant e Hegel, através das filosofias de Bradley e Mc Taggart. Mais tarde, sob a influência de Moore, acaba por rejeitar estas doutrinas através da análise lógica. Sob este aspecto, sua Teoria das Descrições ilustra muito bem este movimento.

Russell começa a se preocupar com problemas filosóficos aos quinze anos de idade. $\mathrm{O}$ que o motiva inicialmente nesta direção são suas dúvidas em relação aos dogmas religiosos. Como, todavia, ele também se interessa pelas matemáticas, as questões religiosas vão sendo, aos poucos, substituídas por questões ligadas à natureza das matemáticas. Estas últimas acabam também substituídas por questões fil osóficas de caráter mais geral. Desse modo, logo depois de ingressar em Cambridge, em 1890, Russell vende todos os seus livros de matemática e se dedica integral mente à filosofia.

Na universidade, seus tutores são J. Ward, que segue a orientação kantiana, e G. Stout, de tendência hegeliana. O pensador que exerce maior influência sobre Russell no período é, contudo, o hegeliano McTaggart. Embora tenha tentado, de início, resistir a esta influência, Russell termina por aderir, em 1894, a uma metafísica que constitui um misto de kantismo e hegelianismo. A dissertação que tem de redigir na época, para cumprir seus deveres acadêmicos, trata da questão dos fundamentos da geometria e tenta defender os resultados da estética transcendental kantiana diante do desafio criado pelo aparecimento das geometrias não-euclidianas. Entre 1896 e 1898, Russell se dedica à elaboração de uma dialética das ciências, em estilo hegeliano. Antes, entretanto, de publicar os resultados desta pesquisa, rejeita a filosofia idealista e muda totalmente a direção de seus estudos.

Ao tomar esta atitude, ele se inspira na revolta de Moore contra o ideal ismo, apesar dos objetivos de ambos serem diferentes. Moore quer defender o realismo do senso comum, ao passo que Russell deseja

${ }^{5}$ As informações históricas sobre a evolução do pensamento de Russell foram extraídas das seguintes obras: B. Russell, Meu pensamento filosófico, (trad. de B. Silveira), São Paulo: Cia Editora Nacional, 1960, 1-4 (cap. 1); J. A. PAssmore, Hundred Years Philosophy, Harmondsworth (Middlesex, England): Penguin Books, 1980, 213 ss. 
refutar a metafísica monista. Moore pretende mostrar que os fatos são independentes do conhecimento que temos deles, e que a parafernália cognitiva kantiana, formada pelas de intuições puras a priori e pelas categorias, é dispensável. Russell concorda de boa vontade com Moore, mas está mais interessado em questões puramente lógicas.

Em 1900, Russell escreve U ma exposição crítica da filosofia de Leibniz. Ali, ele argumenta que a chave para compreender a filosofia de Leibniz está na sua crença de que todas as proposições podem ser reduzidas à forma S é P. Isto envolve uma concepção específica das relações entre os termos da proposição. Com efeito, tais relações passam a ser propriedades destes termos. Consideremos a proposição $x$ está relacionado a y. Se a relação de $x$ com y é uma propriedade de $x$, então $x$ e y não são real mente distintos. $O$ elemento $y$, que se relaciona com $x$, torna-se um aspecto do próprio $x$. Levando este raciocínio às suas últimas conseqüências, podemos dizer que x é um atributo da Realidade como um todo. $E$ isto equivale a um idealismo monista absoluto. A importância de Leibniz está justamente em ter detal hado as implicações metafísicas da análise da proposição em termos de uma substância (sujeito) e seu atributo (predicado). Para Russell, esta doutrina, que envolve a idéia de que as relações só podem ser internas, é suposta pelos sistemas de Spinoza, Hegel e Bradley. Com isso, Russell consegue libertar-se da idéia de $A$ bsoluto e da sua seqüela, a concepção do mundo como mera aparência. A partir de agora, o mundo, assim como as idéias platônicas, pode existir independentemente de nós. Em oposição ao monismo idealista, Russell conclui que há uma pluralidade de objetos e que as relações entre os termos são externas. Tais resultados, convém lembrar, são obtidos através da análise lógica.

Ainda nesta época, Russell entra em contato com os trabalhos lógicos de Peano, que facilitam sua compreensão da definição de número, elaborada por Frege muitos anos antes. A través desta definição, os números são trabal hados em termos puramente lógicos, como ou, não, todo e al gum, deixando de ser objetos independentes. Mais uma vez, a análise lógica revela-se extremamente útil na redução das entidades utilizadas numa dada explicação teórica.

Em 1903, Russell publica Os princípios da M atemática, em que, contra Kant, tenta explicar como pode ser realizado o programa de construir a matemática em termos logicistas. Nesta obra, el e oferece uma primeira versão de sua análise do mecanismo de denotação numa proposição cujo sujeito é uma descrição definida. Ele pensa que, quando um conceito denota, ocorre numa proposição que não é sobre o conceito, mas sobre a coisa a que se refere o conceito. A proposição encontrei um homem, por exemplo, não é sobre um homem, mas sobre uma coisa determinada (um homem efetivo). Assim, a proposição o rei da Inglaterra é sábio envolve a função proposicional $x$ é sábio e a descrição definida o rei da Inglaterra, que ocupa a posição de sujeito. De acordo com a 
análise de Russell, esta proposição significa o homem denotado pela frase o rei da Inglaterra é sábio ${ }^{6}$. Esta perspectiva está ligada aos trabalhos de Brentano, M einong e M oore. Embora pareça correta à primeira vista, ela envolve conseqüências indesejáveis. Foram elas que provocaram o aparecimento da nova teoria da denotação apresentada em 0 n D enoting. Vejamos como.

Inspirando-se nos escolásticos, Brentano pensa que a principal característica de um fenômeno psíquico éa intencional idade, ou seja, a relação a um conteúdo, a direção para um objeto ou objetividade imanente. A presença intencional é exclusiva dos fenômenos psíquicos. Trata-se de uma antiga doutrina escolástica que, em sua obra Psicologia de um ponto de vista empírico, publicada inicialmente em 1874, Brentano expande e aplica a todos os fenômenos psíquicos ${ }^{7}$. Para ele, todo fenômeno psíquico contém em si algo a título de objeto, mas cada um à sua maneira. Assim, numa representação, o objeto é a coisa representada; num juízo, o objeto é aquilo que é afirmado ou negado ${ }^{8}$. Ao analisar os juízos simples, ele afirma que todos podem ser reduzidos a juízos existenciais. O juízo alguns cisnes são negros, por exemplo, equivale a existem cisnes negros, ao passo que o juízo nenhum cisne é negro equivale a cisnes negros não existem. Os objetos que constituem o conteúdo de ambos os juízos são os cisnes negros ${ }^{9}$. Esta análise funciona bem no caso de objetos existentes. Mas, se considerarmos um juízo como nenhum círculo é quadrado, as coisas se complicam. Com efeito, ele equivale a círculos quadrados não existem e os objetos que constituem o conteúdo de tal juízo são os círculos quadrados. Estes últimos acabam de ter sua existência negada e não podem constituir o conteúdo de um ato psíquico.

Para superar esta dificuldade, Meinong, aluno de Brentano, elabora a teoria dos objetos em sua obra Investigações na Teoria dos 0 bjetos e na Psicologia (1904) ${ }^{10}$. De acordo com a mesma, podemos distinguir três elementos num dado fenômeno psíquico: o ato mental , o conteúdo do ato mental e o objeto do ato mental. Para Meinong, Brentano identifica indevidamente o conteúdo com o objeto do ato mental. Como resultado desta identificação, aquilo que está diante da mente, ou seja, o seu objeto, surge como um elemento componente da apreensão do objeto pela mente, ou seja, o seu conteúdo. Se distinguirmos entre objeto e conteúdo, constataremos que o ato mental de pensar existe mesmo

${ }^{6}$ Cfr. B. Russell, The Principles of Mathematics. London: Allen \& Unwin, 1903, 53-64.

7 Cf. F. Brentano, Psychologie du point de vue empirique, (trad. M. de Gandillac), Paris: Aubier, 1944, 30; 102.

8 Cfr. Brentano, op. cit., 102.

${ }^{9}$ Cfr. Brentano, op. cit., 218.

$10 \mathrm{Em}$ virtude de não termos tido acesso aos textos do próprio Meinong, as informações sobre ele foram extraídas de PASSMORE, op. cit., 180-5, e de P. EdWARDS (ed. in chief), Encyclopaedia of Philosophy, vol. 5, New York: The MacMillan Co \& the Free Press; London: Collier-MacMillan, 1967, 261. 
quando estivermos pensando a respeito de um objeto não-existente. Neste caso, o ato de pensar se refere a um objeto determinado, mas não possui conteúdo. Assim, no juízo os círculos quadrados não existem, os círculos quadrados constituem o objeto deste juízo, embora não possam corresponder a seu conteúdo. Este último pode ser definido como a qualidade que um dado ato mental possui de poder apontar para um determinado objeto e não para outro. Nesta perspectiva, o conteúdo constitui não uma coisa independente, mas uma propriedade do ato mental. Em conseqüência, al guns dos objetos do ato de pensar existem, como, por exemplo, um círculo vermelho; outros destes objetos meramente subsistem, como, por exemplo, a diferença entre um círculo e um quadrado; outros objetos, contudo, não existem enão subsistem, mas estão "fora do ser", como, por exemplo, o círculo quadrado. Estes objetos não estão sequer sujeitos à lei de não contradição, pois podemos dizer deles, por exemplo, que são vermelhos ou que não são vermelhos. Todas estas "entidades" constituem instâncias dos objetos auja teoria é elaborada por Meinong.

De acordo com John Passmore, a abordagem de Meinong atrai a atenção dos filósofos britânicos por duas razões principais. Primeiro, porque mantém rigorosamente a objetividade dos fatos, coisas, números, universais, relações e distinções modais. Segundo, porque esta objetividade é preservada a um custo considerável: nosso universo surge como povoado por uma grande variedade de entidades com propriedades surpreendentes. A partir de Meinong, a questão que se coloca para os filósofos britânicos é a de saber se podemos preservar a objetividade sem ter de assumir estas conseqüências paradoxais ${ }^{11}$.

Em A natureza do juízo, artigo publicado em 1899, Moore tenta responder a esta questão na mesma linha de Brentano e Meinong. Em sua análise do juízo, Moore argumenta que ele versa sobre conceitos, que são eternos e imutáveis. Com isso, rompe corajosamente com o psicologismo da tradição empirista britânica. Moore define a proposição como uma relação entre conceitos. E a proposição verdadeira é idêntica com a realidade à qual corresponde. A neve é branca, por exemplo, em nada difere da realidade brancura da neve. Ser verdadeira é uma propriedade simples e intuitiva de uma determinada proposição. Algumas proposições são verdadeiras e outras, falsas, assim como al gumas rosas são vermelhas e outras, brancas ${ }^{12}$. Esta abordagem também está sujeita a dificuldades semelhantes às enfrentadas por Brentano e Meinong. De fato, o estatuto de conceitos como círculo quadrado continua difícil de explicar aqui, bem como o de uma proposição como 0 círculo quadrado não é quadrado, que, pela teoria de Moore, se identifica com uma realidade que, em última instância, não existe.

11 Cf. Passmore, op. cit., 185.

${ }^{12}$ Cfr. G. E. Moore, The Nature of J udgment, in: Th. Baldwin (ed.), G. E. Moore: Selected Writings. London and New York: Routledge, 1993, 4-5. 
Inspirada nos autores acima, a análise de Russell em Princípios da $M$ atemática padece de dificuldades semelhantes. De acordo com ela, a proposição o rei da França é calvo deve ser equivalente a o homem denotado pela frase 'o rei da França' é calvo. Mas não existe o homem denotado pela frase ' 0 rei da França'. Dele podemos igualmente dizer que é calvo e que não é calvo. Como proceder neste caso? Ao formular esta análise, Russell ainda está entusiasmado com o realismo defendido por Moore, que permite acreditar na existência das coisas do mundo e suas respectivas propriedades, abrindo inclusive espaço para um mundo de entidades abstratas do tipo das idéias platônicas. A dificuldade mencionada, porém, parece constituir uma falsificação dos "conceitos" de Moore e dos "objetos" de Meinong. Ela constitui um dos fatores que afastam Russell desta postura realista extremada, incentivando a busca de uma abordagem alternativa.

Na mesma época, Frege e Bradley também oferecem análises das descrições definidas em posi ção de sujeito, mas elas parecem insuficientes para Russell. Frege, por exemplo, no famoso artigo Sobre sentido e referência, de 1892, recorre ao conceito de pressu posição semântica para explicar o mecanismo referencial das descrições definidas. De acordo com Frege, uma proposição como o rei da França é cal vo envolve dois níveis. O primeiro deles é o da asserção da proposição. O segundo é o da pressuposição semântica feita pela asserção que, no caso, corresponde a existe um e somente um rei da França. Assim, quando afirmamos a primeira, estamos pressupondo semanticamente a segunda. As relações lógicas entre estas proposições são as seguintes: se a proposição pressuposta é verdadeira, então a descrição definida possui sentido (Sinn) e significado (Bedeutung) ${ }^{13}$, a proposição asserida possui sentido e valor de verdade e a bivalência é respeitada; se a proposição pressuposta é falsa, então a descrição definida possui sentido, mas não possui significado, a proposição asserida possui sentido, mas não possui valor de verdade, ea bivalência é desrespeitada. No exemplo em questão, como a proposição pressuposta existe um e somente um rei da França é falsa, a

${ }_{13}$ De acordo com Frege, o significado de um signo corresponde ao objeto designado pelo signo. Já o sentido de um signo corresponde ao modo de apresentação do significado. Assim, o significado de o mestre de Aristóteles e 0 discípulo de Sócrates é o indivíduo Platão. O sentido de o mestre de Aristóteles e o de o discípulo de Sócrates correspondem a diferentes maneiras de apresentar o indivíduo Platão. No caso de uma proposição, como, por exemplo, o mestre de Aristóteles é grego, o significado é o valor de verdade (no caso, o verdadeiro) e o sentido é o pensamento expresso pela proposição (no caso, a circunstância de o mestre de Aristóteles ser grego). Ver G. FrEGE, Sobre sentido e referência, in: IDEM, Lógica e Filosofia da Linguagem, (sel., intr., trad. e notas de P. Alcoforado), São Paulo: Cultrix/EDUSP, 1978, 59-86. Alguns comentadores de Frege traduzem Bedeutung por referência, mas isto vai contra o espírito da terminologia do autor, que usa esta palavra em um sentido deliberadamente diferente do tradicional. Assim, para seguir o espírito da terminologia de Frege, a tradução mais adequada envolveria usar a palavra significado num sentido deliberadamente diferente do tradicional. 
descrição definida o rei da França não possui significado, a proposição asserida o rei da França é calvo não é nem verdadeira nem falsa, ou seja, não possui valor de verdade, e a bivalência é desrespeitada. Frege pensa que este fenômeno decorre de uma imperfeição intrínseca à linguagem natural. Para evitar situações deste tipo numa linguagem científica, ele propõe que se estipule que as descrições definidas do tipo de o rei da França ou o maior número da série 2,9 2,99 2,999 2,9999 etc. tenham como significado o conjunto vazio. É certo que Frege caminha no sentido de resolver questões metafísicas através da análise lógica das expressões, como faz Russell. Sua solução, porém, desagrada a este último por dois motivos principais. Primeiro, ela admite, pelo menos na linguagem natural, casos em que o fracasso referencial envolva o desrespeito à bivalência (o rè da França écalvo não énem verdadeira nem falsa). Segundo, ela adota uma solução muito artificial para estes casos numa linguagem científica, estipulando que o significado das descrições vácuas deve ser o conjunto vazio (o rei da França é calvo é uma proposição falsa, se o significado de o rei da França é o conjunto vazio). Estas inconveniências não deveriam estar presentes numa solução adequada do problema.

Bradley, por sua vez, rejeita a concepção tradicional de que o juízo se divide em sujeito e predicado, como os lógicos de sua época, mas oferece em troca uma análise metafísica ${ }^{14}$. Para Bradley, um juízo como todos os cisnes são negros equivale a a Realidade é tal que os cisnes são de cor negra: Todo juízo envolve uma unificação, ao atribuir um dado predicado à Realidade. Os predicados podem ser muitos, mas a Realidade é única. Nenhuma outra análise do juízo é capaz de reconciliar a unidade da atribuição com a diversi dade de predicados. Em virtude disso, todos os juízos possuem a mesma forma, que consiste em afirmar um conteúdo ideal da Realidade. Nesta perspectiva, juízos do tipo 0 círculo quadrado não existe ou o rei da França não existe devem ser analisados respectivamente como a Realidade é tal que exclui a conexões de 'círculo' e 'quadrado' ea Realidade é tal que exclui as conexões de 'monarquia' e'França'. Isto tem a dupla vantagem de impedir que usemos as descrições vácuas em juízos como o círculo quadrado éredondo ou o rei da França é calvo e elimina a aparente referência a entidades irreais, com o conseqüente desrespeito à bivalência. Embora apresente estas vantagens, a solução de Bradley desagrada a Russell por seu caráter idealista, que enfatiza excessivamente a Realidade, e por isso postula uma forma lógica única para a diversidade das proposições da linguagem.

Nos anos de 1903 e 1905, Russell elabora a Teoria das Descrições, que pretende resolver o impasse criado. De um lado, Brentano, Meinong, Moore e ele próprio, na fase dos Princípios da M atemática, com uma solução que, embora preserve a objetividade, postula um excesso de

\footnotetext{
${ }^{14} \mathrm{Em}$ virtude de não termos tido acesso aos textos de Bradley, as informações sobre ele foram extraídas de PASSMORE, op. cit., 60-71.
} 
entidades eacaba por desrespeitar a bivalência'5. De outro, Fregee Bradley, com soluções al ternativas. O primeiro consegue preservar a objetividade, mas também desrespeita a bivalência e propõe uma solução muito artificial através do conjunto vazio. O segundo consegue preservar a bivalência, mas adota uma postura idealista, que reduz todas as proposições a uma única forma lógica, envolvendo a atribuição de diferentes predicados à mesma "Real idade". Como Russell, Fregee Bradley desconfiam da forma gramatical da proposição, que pode nos desorientar na tentativa de desvelar a forma lógica profunda. Mesmo assim, eles parecem ter-se deixado influenciar pela mesma forma gramatical em suas análises. A solução de Russell pretende superar estas dificuldades todas e, ao mesmo tempo, ser realista, preservar a bivalência e respeitar a diversidade das formas lógicas das proposições, sem ser artificial.

Como se pode ver, o ponto de partida de Russell em On D enoting é formado pelo problema da denotação e pelo confronto das teorias alternativas anteriormente apresentadas. A questão da denotação, embora muito difícil, é relevante para a lógica, a matemática e a teoria do conhecimento. Ela corresponde ao conhecimento por descrição, em que não temos acesso direto à coisa, devendo contentar-nos apenas com uma descrição da mesma. É necessária uma solução que preserve o realismo e a bivalência, sem recorrer a artificialismos. São estes valores que motivam Russell. Para realizá-los, o filósofo britânico conta com um grande arsenal de técnicas lógicas novas, estabelecidas pelos trabalhos de Peano e, principalmente, de Frege.

Se este é o ponto de partida de Russell, podemos dizer que o auditório a que se dirige sua argumentação é a comunidade filosófica em geral, destacando-se ali aquela parcela efetivamente interessada na questão do mecanismo referencial das descrições definidas em posição de sujeito. Alguns exemplos de indivíduos pertencentes a tal auditório são Brentano, Meinong, Frege, Moore, Bradley etc. Como se vê, trata-se de um auditório de elite, com pretensões a auditório universal. Daí o formato predominantemente lógico da argumentação de Russell.

\section{III - A Teoria das Descrições (On Denoting, pp. 480-482)}

Estamos agora no segundo momento do processo de análise argumentativa. Vejamos, portanto, em que consiste a solução de Russell. Para apresentá-la, ele introduz a noção primitiva ' $F(x)$ ' é sempre VER-

${ }^{15}$ Em On Denoting, Russell também comenta rapidamente a solução de MacColl, que equipara à de Meinong. Cfr. B. Russell, On Denoting. Mind, vol. 14 (1905), 491. 
DADEIRA . Ela se baseia no conceito de função proposicional, representado simbolicamente por $\mathrm{F}(\mathrm{x})$, que serve para os casos em quea palavra todo, ou nada ou algo faz parte do argumento. Quando uma destas palavras está presente, temos o seguinte:

$F($ tudo) equivale a ' $F(x)$ ' é sempre verdadeira;

$F$ (nada) equivale a ' $F(x)$ ' é sempre falsa ;

$F(a l g o)$ equivale a ' $F(x)$ ' é al gumas vezes verdadeira ${ }^{16}$.

Em termos mais concretos, isto pode ser ilustrado da seguinte maneira:

Tudo é belo equivale a ' $x$ é belo' é sempre verdadeira;

$N$ ada é belo equivale a ' $x$ é belo' é sempre falsa;

A lgo é belo equivale a 'x é belo' é algumas vezes verdadeira.

Usando o simbolismo atual, teríamos, respectivamente:

(x) $\mathrm{x}$ é belo [para todo $\mathrm{x}, \mathrm{x}$ é belo];

(x) $x$ não é belo [para todo $x, x$ não é belo];

(\$x) $x$ é belo [existe um $x$ tal que $x$ é belo].

A noção primitiva que acabamos de caracterizar também pode ser aplicada a casos mais complexos, envolvendo expressões como todo homem, nenhum homem ou algum homem:

$F$ (todo homem) equivale a se $x$ é humano, então " ' $F(x)$ ' éverdadeira" é sempre verdadeira;

$F$ (nenhum homem) equivale a 'se $x$ é humano, então "' $F(x)$ ' é fal sa" é sempre verdadeira;

$\mathrm{F}$ (um homem) ${ }^{17}$ equivale a $\mathrm{X}$ é humano $\mathrm{e}^{\prime} \mathrm{F}(\mathrm{X})^{\prime}$ ' é algumas vezes verdadeira. ${ }^{18}$

Suponhamos que a função proposicional $F(x)$ seja equivalente $a x$ é mortal. Neste caso, teríamos o seguinte quadro:

Todo homem é mortal equivale a 'se $\mathrm{x}$ é humano, então $\mathrm{x}$ é mortal' é sempre verdadeira [no simbolismo atual: $(\mathrm{x})(\mathrm{Hx}=>\mathrm{Mx})$ ];

$N$ enhum homem é mortal equivalea "se $x$ é humano, então ' $x$ émortal' é fal sa" é sempre verdadeira [no simbolismo atual: $(x)(H x=>M x)$ ]; Algum homem é mortal equivale a ' $x$ é humano e $x$ é mortal' é al gumas vezes verdadeira [no simbolismo atual: $(\$ x)(H x \& M x)$ ];

Segundo Russell, o caso mais complexo de todos surge quando uma descrição definida ocupa a posição do argumento. Suponhamos que a descrição seja o pai de Carlos II. Ela indica um indivíduo único que

\footnotetext{
16 Russell, op. cit., 480.

17 No sentido de algum homem.

18 Russell, op. cit., 481.
} 
possui a propriedade de ser pai de Carlos II. Como, porém, analisá-la sem que a descrição reapareça do lado direito da equivalência? Embora Russell não explicite isso, se a descrição reaparecesse, teríamos algo como

$F$ (o pai de Carlos II) equivalea ' $x$ éo pai de Carlos II ef $(x)$ ' éalgumas vezes verdadeira.

Nesta análise, a descrição definida manteria o caráter de expressão referencial do lado direito, denotando o indivíduo único que possui a propriedade de ser pai de Carlos II. E teríamos problemas indesejáveis com descrições vazias como o rei da França, já que as mesmas denotariam entidades inexistentes (no caso, o indivíduo único que possui a propriedade de ser rei da França). Para evitar isso, Russell oferece a seguinte solução:

$\mathrm{F}$ (o pai de Carlos II) equivale a 'x gerou Carlos II e x éúnico e $F(x)$ ' é algumas vezes verdadeira.

Aqui, é digno de nota que a descrição definida o pai de Carlos II desaparece na forma analisada do lado direito da equivalência, sendo substituída por uma conjunção de duas funções proposicionais, a saber, $x$ gerou Carlos II e x é único. Para poder substituir o pai de Carlos II, estas duas funções devem ser capazes de realizar as duas tarefas lógicas cumpridas pela descrição: a) permitir o reconhecimento do indivíduo a que ela se refere (tarefa realizada por $x$ gerou Carlos II, já quex é pai de Carlos II se e somente se x gerou Carlos II); b) marcar o fato de que o indivíduo a que ela se refere é único (tarefa realizada por x é único). Ora, as duas funções proposicionais fazem exatamente isto. A descrição definida revela-se, portanto, dispensável na forma analisada do lado direito da equivalência e ficamos livres da dificuldade criada pelas descrições vazias. A descrição o rei da França, por exemplo, pode ser substituída pela conjunção x ocupa 0 trono francês e x é único. Ao invés de lidar com a problemática e inexistente entidade única que seria o rei da França, passamos a lidar com uma conjunção de funções proposicionais, que será verdadeira quando encontrarmos um indivíduo que satisfaça a ambas. Como tal indivíduo não existe, podemos simplesmente dizer que a conjunção $x$ ocupa o trono francês e $x$ é único é falsa, sem nos preocuparmos com o problemático estatuto da descrição o rei da França.

Vejamos agora um caso completo. Se a função $F(x)$ é, por exemplo, $x$ foi executado, teremos a seguinte análise:

0 pai de Carlos II foi executado equivale a 'x gerou Carlos II ex é único e $x$ foi executado' é al gumas vezes verdadeira (no simbolismo atual: $(\$ x)[G x \& U x \& E x])$. 
A função proposicional x éúnico pode ter uma formulação logicamente mais rigorosa:

$x$ é único equivale a 'se y gerou Carlos II, então y é idêntico a $x$ ' é sempre verdadeira [no simbolismo atual: $(y)(G y=>y=x)$ ].

Se $x$ é único, então qualquer indivíduo y do qual se possa dizer que gerou Carlos II deve ser idêntico a $x$. É isto que nos diz a equivalência acima. Portanto, a forma completamente analisada da proposição o pai de Carlos II foi executado é:

\section{"x gerou Carlos II \\ e}

'se y gerou Carlos II, então y éidêntico a x' é sempre verdadeira e

$x$ foi executado" é algumas vezes verdadeira ${ }^{19}$

(no simbolismo atual: $(\$ x)[G x \&(y)(G y=>y=x) \& E x]$ ).

A análise acima também faz desaparecer a descrição definida, evitando assim, por intermédio da conjunção de funções proposicionais, as dificuldades criadas pelas descrições vazias ${ }^{20}$.

A teoria de Russell tem uma conseqüência importante, no que diz respeito à negação. Há uma ambigüidade quando negamos proposições contendo descrições definidas na posição de sujeito. N estes casos, a partícula não pode ser entendida de duas maneiras diferentes. Para explicar isso, Russel faz uma distinção entre ocorrência primária e secundária da descrição. Suponhamos a proposição o Rei da França NÃ O é calvo. Ela pode significar:

a) existe um $x$ tal que $x$ ocupa o trono francês e $x$ é único e $x N A ̃ O$ é calvo (em símbolos atuais: $(\$ x)[T x \&(y)(T y=>(y=x)) \& \sim C x])$.

\footnotetext{
19 RUSSELL, op. cit., 481-2

${ }^{20} \mathrm{Em}$ um momento bem posterior dessa discussão, C. Wright apresenta um argumento do qual Russell não estava consciente e que torna a questão da denotação bem mais complexa do que parece à primeira vista. Russell considera que as proposições o pai de Carlos II foi executado e existe uma entidade $x$ tal que $x$ gerou Carlos II e $x$ é único e $x$ foi executado são equivalentes. Representemos a primeira por $E(d)$, em que $d$ corresponde a $o$ pai de Carlos II e $E(x)$, a $x$ foi executado. A segunda, como sabemos, pode ser representada por $(\$ x)[G x$ $\&(y)(G y \Rightarrow y=x) \& E x]$. Abreviemo-la para $S F(x)$, para indicar que se trata de um somatório de funções proposicionais. A equivalência obtida por Russell é, então: $E(d)$ ó $S F(x)$. O problema levantado por Wright é o seguinte. Com base nesta equivalência, Russell pensa que pode concluir que o lado direito da equivalência tem prioridade e que, por isso, o lado esquerdo é enganador (a descrição deve desaparecer com a análise). Mas nada impede que atribuamos a prioridade ao lado esquerdo da equivalência, o que torna o lado direito enganador (a descrição exerce uma autêntica função denotativa, que estaria sendo mascarada pelo somatório de funções proposicionais). Cfr. C. WRIGHT, Frege's Conception of Numbers as Objects, Aberdeen: Aberdeen Un. Press, 1983, 31-2.
} 
Aqui, estamos afirmando que existe um único indivíduo que ocupa o trono francês e NÃ O é calvo (proposição falsa). Quando isto acontece, Russell nos diz que temos uma ocorrência primária da descrição definida;

b) N Ã $O$ é $o$ caso que ' $x$ ocupa 0 trono francês e $x$ é único e $x$ é calvo' (em símbolos atuais: $\sim(\$ x)[T x \&(y)(T y=>(y=x)) \& C x])$. Aqui, estamos afirmando que NÃO existe um único indivíduo que ocupe o trono francês e seja calvo (proposição verdadeira). Quando isto acontece, Russell nos diz que temos uma ocorrência secundária da descrição definida. ${ }^{21}$

Em síntese, a análise de Russell mostra que, contrariamente ao que pensa Frege, a descrição definida em posição de sujeito não é uma expressão denotativa autêntica e simplesmente desaparece na forma analisada, sendo substituída por uma articulação de funções proposicionais.

Do ponto de vista da teoria do conhecimento, a principal conseqüência da teoria de Russell está na sua explicação do conhecimento por descrição. N esta situação, conhecemos as propriedades da coisa sem ter contato direto com a própria coisa. Em virtude disso, as proposições contendo a descrição da coisa na posição de sujeito são decomponíveis em funções proposicionais expressando as propriedades da coisa. Assim, não conhecemos uma única proposição de que a própria coisa seja um constituinte ${ }^{22}$.

\section{IV - Principais aspectos da argumentação em On Denoting}

Conforme mencionado anteriormente, os principais aspectos argumentativos considerados no texto a ser analisado são a estratégia geral de argumentação, os esquemas argumentativos, os procedimentos heurísticos e a convergência dos argumentos. Vejamos cada um deles em $0 \mathrm{n}$ D enoting.

Por estratégia geral de argumentação entendemos a maneira pela qual o autor organiza e combina seus argumentos, formando um todo coerente na defesa de sua tese principal. A plicando este conceito a 0 n D enoting, podemos dizer que a estratégia geral de argumentação de Russell consiste na tentativa de obter a adesão de seu auditório, mostrando que o problema da denotação é relevante, apresentando de maneira técnica

21 Russell, op. cit., 489.

22 Russell, op. cit., 498. 
sua própria teoria e recolhendo evidências a favor da mesma através da conjunção dos seguintes fatores: a) as dificuldades enfrentadas pelas teorias alternativas; b) as vantagens da nova teoria em superar estas dificuldades; c) a inevitável complexidade de qualquer teoria sobre a denotação.

Para implementar tal estratégia, Russell divide o texto de $0 \mathrm{n}$ D enoting em cinco partes distintas:

1a Parte: Introdução (envolvendo a captatio ben evolentiae e a partitio) (On Denoting, pp. 479-80);

2a Parte: Exposição da teoria (propositio) (O n D enoting, pp. 480-2);

3a Parte: Crítica das teorias alternativas de Meinong e de Frege (podendo ser considerada um análogo da al tercatio) (On D enoting, pp. 482-8);

4a Parte: A presentação das vantagens em favor da teoria (podendo ser considerada uma espécie de probatio) (0 n D enoting, pp. 488-92); ${ }^{23}$

5a Parte: Epílogo (incluindo a apresentação da principal conseqüência filosófica da teoria e um último argumento a seu favor, baseado na constatação de que uma teoria da denotação deve ser inevitavelmente complexa) (O n D enoting, pp. 492-3).

Em cada uma das partes acima, Russell utiliza esquemas argumentativos específicos. A expressão esquemas argumentativos se refere aos argumentos particulares utilizados pelo autor no desenvolvimento do processo de demonstração de sua tese principal. Para a análise de tais esquemas, basear-nos-emos na classificação de Perel man \& Olbrechts-Tyteca, que se encontra no Traité de l'A rgumentation. Assim, na 1 a Parte de On D enoting (pp. 479-80), Russell define frase denotativa (denoting phrase) e faz uma importante distinção entre conhecimento por contato direto (acquaintance) e conhecimento por descrição (description), mostrando que esteúltimo é obtido por meio de frases denotativas. A definição de frase denotativa é feita através do esquema argumentativo perelmaniano da identidade ${ }^{24}$. A distinção entre conhecimento por contato direto e conheci-

${ }^{23}$ O trecho que vai da $2^{a}$ à 4 a Parte (On Denoting, pp. 480-92) constitui o desenvolvimento do texto de Russell, correspondendo a uma confirmatio em sentido tradicional, já que envolve a propositio, a altercatio e a probatio

${ }^{24} \mathrm{Na}$ argumentação, os esquemas argumentativos da identidade envolvem, entre outros, a definição, a análise e a tautologia. As definições são procedimentos que visam identificação completa, podendo ser normativas (indicam a maneira pela qual a palavra deve ser usada), descritivas (indicam o sentido conferido a uma palavra numa dada circunstância histórica), de condensação (indicam elementos essenciais da definição descritiva) ou complexas (combinam elementos das três espécies precedentes). Cf. Ch. Perelman \& L. Obrechts-Tyteca, Traité de l'argumentation, tome premier, Paris: PUF, 1958, 282-3. A definição russelliana parece ser do tipo complexo. 
mento por descrição é feita com base no esquema perelmaniano da dissociação de noções ${ }^{25}$. Para mostrar que só conhecemos certos objetos por descrição, Russell usa o esquema argumentativo da ilustração (conhecemos o centro de massa do sistema solar por descrição e não por contato direto) ${ }^{26}$.

Na 2a Parte (0 n D enoting, pp. 480-2), que envolve a apresentação da Teoria das Descrições, Russell adota os esquemas argumentativos da identidade e reforça os mesmos através do uso de ilustrações. Sua abordagem envolve também o princípio segundo o qual toda descrição definida pode ser substituída por uma função proposicional que Ihe é logicamente equivalente, da mesma forma que a descrição 0 pai de Carlos II é substituível por x gerou Carlos II. Este importante princípio é justificado apenas através do esquema argumentativo do exemplo27, fornecido por esta última substituição.

$\mathrm{Na} 3^{a}$ Parte (0 n D enoting, pp. 482-8), que envolve a argumentação em torno das dificuldades das teorias alternativas, podemos identificar três subpartes. Na primeira, Russell faz uma crítica das dificuldades das teorias alternativas de Meinong e Frege ( $0 \mathrm{n}$ D enoting, pp. 482-4). $\mathrm{Na}$ segunda, mostra três enigmas lógicos que não são resolvidos pelas teorias alternativas ( $\mathrm{n}$ D enoting, pp. 484-5). Na terceira, faz uma crítica à distinção fregiana entre sentido (Sinn) e significado (Bedeutung) $(0 \mathrm{n}$ D enoting, pp. 485-8).

Na primeira subparte (O n D enoting, pp. 482-4), Russell adota os esquemas argumentativos da contradição ${ }^{28}$. Tais esquemas procuram estabelecer incompatibilidades nas teorias alternativas de Meinong e Frege, que são acusadas de desrespeitar a lei de contradição. A pesar destas

\footnotetext{
${ }^{25}$ Segundo Perelman, a dissociação de noções se coloca contra uma confusão de elementos díspares numa unidade primitiva que funcionaria como uma mesma concepção. Tais elementos díspares são designados por uma mesma noção. A dissociação de noções quebra isto, determinando um remanejamento mais ou menos profundo dos dados conceituais que servem de fundamento à argumentação. Toda filosofia nova supõe a elaboração de um aparato conceitual em que a parte mais original resulta de uma dissociação de noções, permitindo resolver os problemas que o filósofo colocou para si. Cfr. Perelman \& Olbrechts-Tyteca, op. cit., tome second, 551-4.

26 Para Perelman, a ilustração não deve ser confundida com o esquema argumentativo do exemplo. Este último constitui uma ligação que funda a estrutura do real com base num caso particular. Assim, enquanto o exemplo serve para fundar uma regra, a ilustração reforça a adesão à regra, fornecendo instâncias esclarecedoras do enunciado geral envolvido. Ibidem, 481.

27 Conforme indicado na nota anterior, o esquema argumentativo do exemplo pressupõe a possibilidade de uma generalização a partir de casos particulares. $\mathrm{O}$ argumento pelo exemplo assume muitas vezes a forma do argumento que vai do particular ao particular. Ibidem, 471-4.

${ }^{28}$ Quando se usam tais esquemas argumentativos, de acordo com Perelman, o objetivo é mostrar que as teses que se combatem conduzem a uma incompatibilidade. Ibidem, tome premier, 263.
} 
teorias serem diferentes, Russell mostra que ambas apresentam o mesmo resultado indesejável: de acordo com elas, uma proposição como 0 atual rei da França é calvo não é nem verdadeira nem falsa, quebrando a lei de contradição.

Na segunda subparte (0 n D enoting, pp. 484-5), são apresentados três enigmas que, segundo Russell, não são adequadamente resolvidos pelas teorias de Meinong eFrege. Os esquemas argumentativos utilizados são novamente os da contradição, pois, em todos os três casos, ele tenta estabelecer alguma incompatibilidade. No primeiro enigma, Russell mostra que a proposição George IV desejava saber se Scott era 0 autor de W averley paradoxalmente equivale à proposição G eorge IV desejava saber se Scott era Scott. Isto é assim porque Scott é o autor de Waverley, de modo que seu nome - Scott - pode substituir a descrição 0 autor de W averley em qualquer situação. A falsidade de G eorge IV desejava saber se Scott era Scott é tão óbvia que, através da incompatibilidade criada, Russell parece estar tentando reduzir seus adversários ao ridícul ${ }^{29}$. Isto fica bem ilustrado pelo comentário irônico que Russell acrescenta logo após a exposição do primeiro enigma: todavia um interesse na lei da identidade dificilmente pode ser atribuído ao primeiro caval heiro da Europa ${ }^{30}$. No segundo enigma, Russell mostra que, se ou uma proposição ou sua negação deve ser verdadeira, então as proposições o presente rei da França é calvo e o presente rei da França não é calvo desrespeitam tal princípio, pois não existe o presente rei da França. $A$ incompatibilidade aqui introduzida consiste em mostrar que isto contradiz o princípio lógico do terceiro excluído. Neste ponto, Russell se aproveita para reduzir os hegelianos ao ridículo, sugerindo que, segundo eles, que adoram uma síntese, o atual rei da França deve estar usando uma peruca ${ }^{31}$. No terceiro eúltimo enigma, Russell mostra que se $A$ e $B$ não diferem, supor que exista um objeto como a diferença entre $A$ e $B$, parece também impossível. Com efeito, se tentarmos determinar qual proposição é verdadeira na oposição formada por a diferença entre $A$ e $B$ possui a propriedade $P$ e a diferença entre $A$ e $B$ não possui a propriedade $P$, cairemos numa incompatibilidade do mesmo tipo que a do enigma anterior, pois não existe a diferença entre A e B.

\footnotetext{
${ }^{29} \mathrm{Em}$ Perelman, o esquema argumentativo do ridículo é usado quando se mostra que uma dada tese entra em conflito, sem justificação, com uma opinião admitida. Dizer que uma tese é inadmissível porque suas conseqüências seriam ridículas é uma das mais fortes objeções na argumentação. Trata-se de um procedimento análogo ao da redução ao absurdo em matemática. Ibidem, tome premier, 276-8. Russell está tentando mostrar que a identificação pura e simples do nome próprio Scott com a descrição o autor de Waverley leva a um paradoxo, pois George IV não queria saber se Scott era Scott, mas sim se Scott era o autor de Waverley.

${ }^{30}$ Cf. Russell, op. cit., 485.

31 Ibidem.
} 
Na terceira subparte (0 n D enoting, pp. 485-8), Russell faz uma crítica da distinção fregiana entre sentido e significado, já mencionada anteriormente. Isto envolve novamente o apel o ao esquema argumentativo da contradição, através do qual Russell pretende mostrar que a distinção em questão envolve al gum tipo de incompatibilidade. Para isto, ele introduz três expressões com referências encadeadas e tenta exibir a incompatibilidade envolvida pela distinção entre sentido e significado a partir das relações entre elas. Sejam as expressões abaixo:

[1] o complexo denotativo em [2],

[2] o primeiro verso da 'Elegia' de Gray,

[3] The curfew tolls the knell of parting day ${ }^{32}$.

O encadeamento referencial destas expressões éo seguinte: a descrição [1] se refere à descrição [2], que por sua vez se refere ao verso em [3]. Para explicar a dificuldade envolvida por este encadeamento referencial, Russell usa uma terminologia diferente da de Frege. Como sabemos, este último adota a oposição entre sentido (Sinn) e significado (Bedeutung), enquanto o primeiro adota a oposição entre meaning (significado) e denotation (denotação). A pesar da diferença terminológica, Russell parece entender que meaning corresponde exatamente a Sinn e que den otation corresponde exatamente a Bedeutung. Isto significa que ele adota o esquema argumentativo da identidade para estabelecer esta correspondência terminológica inusitada e confusa. O argumento de Russell, além de basear-se nesta terminologia inadequada, é bastante obscuro. Para acompanhá-lo, tentemos fazer referência a [2] com o auxílio de [1]. Usando o vocabulário de Russell, podemos dizer que a denotação [denotation] do complexo denotativo em [2] éo primeiro verso da 'Elegia' de Gray [1]. Mas a denotação [denotation] do primeiro verso da 'Elegia' de Gray, em [1], é o verso expresso em [3]: The curfew tolls the knell of parting day. Assim, embora queiramos nos referir a [2] através de [1], a denotação de [2], em virtude de sua posição intermediária no encadeamento referencial, nos faz deslizar para [3], tornando fracassada nossa tentativa. Em outras palavras, a expressão a denotação de [1] deveria dar-nos [2], mas de fato nos dá [3]. Neste caso, não temos como nos referir a [2]. Com base nisto, Russell pensa que é possível mostrar a confusão inextricável gerada pel a distinção fregiana. Para ele, a incompatibilidade está em que não conseguiremos preservar a conexão entre significado e denotação e simultaneamente evitar a confusão de um conceito com o outro ${ }^{33}$.

Ainda na terceira subparte, Russell tenta estabelecer mais uma incompatibilidade a partir da distinção fregiana. De acordo com ele, Frege

32 Em tradução livre: o toque de recolher anuncia o som plangente do dia que se vai.

33 Russell, op. cit., 486. 
pensa que apenas a den otação é rel evante, mas o primeiro enigma, acima mencionado, constitui prova formal de que este não é o caso. Com efeito, a proposição Scott era o autor de Waverley possui uma propriedade que não é possuída pela proposição Scott é Scott, já que George IV queria saber se a primeira delas era verdadeira, e não a segunda. Logo, as duas proposições não são idênticas, e o significado de o autor de W averley deve ser tão relevante quanto sua denotação, contrariamente ao que Frege pensa. Devemos, pois, abandonar a distinção.

$\mathrm{Na}$ 4a Parte (O n D en oting, pp. 488-92), em que Russell tenta mostrar as vantagens de sua própria teoria, ele usa os esquemas argumentativos da ilustração e da dissociação de noções. Na solução russelliana do 1o enigma, a proposição G eorge IV queria saber se Scott era 0 autor de W averley é ambígua e pode corresponder a

um e somente um homem escreveu W averley e G eorge IV queria saber se Scott era este homem

ou então a

George IV queria saber se um e somente um homem escreveu W averley e se Scott era este homem.

Temos, claramente, duas ilustrações de aplicações da teoria de Russell. Na primeira delas, já sabemos que um e somente um homem escreveu Waverley. Neste caso, estamos dizendo que George IV quer apenas saber se Scott era este homem. Quando isto acontece, temos uma ocorrência primária da descrição 0 autor de W averley. Na segunda aplicação, também não sabemos que um e somente um homem escreveu Waverley. Neste caso, estamos dizendo que George IV quer saber se al guém escreveu Waverley e se este alguém era Scott. Quando isto acontece, temos uma ocorrência secundária da descrição definida. Como se pode ver, a distinção entre estas ocorrências é feita através do esquema argumentativo da dissociação de noções.

Na solução russelliana do $2^{\circ}$ enigma, a proposição 0 atual Rei da França é calvo é simplesmente falsa, já que não existe um $x$ tal que $x$ reina na França. A negação desta proposição, porém, é ambígua. Em virtude disso, ela é verdadeira, quando interpretada como

NÃO existe um único $x$ que é atual mente Rei da França e x é calvo, e falsa, quando interpretada como

existe um único $x$ que é atualmente Rei da França e x NÃ O é calvo.

As ilustrações acima mostram que a negação pode ocupar dois lugares diferentes na proposição. No primeiro caso, temos uma ocorrência primária e, no segundo, uma ocorrência secundária da descrição. A dissociação de noções é reutilizada aqui. N este ponto, Russell procura 
reforçar sua argumentação, ao comentar ironicamente que, com sua teoria, não somos forçados a concluir que o Rei da França usa peruca ${ }^{34}$.

Na solução russelliana do 30 enigma, a proposição a diferença entre $A$ e $B$ não existe não envolve contradição, pois equivale à proposição não existe um e somente um $x$ tal quex éa diferença entre $A$ e $B$. Como não existe a diferença entre $A$ e $B$, a proposição a diferença entre $A$ e $B$ possui a propriedade $P$, envolvida por este enigma, é falsa. $O$ esquema argumentativo utilizado por Russell ainda é o da ilustração, mostrando agora que proposições sobre não-entidades envolvem apenas funções proposicionais e que tais proposições são simplesmente falsas. Neste ponto, Russell aproveita para considerar a seguinte formulação do argumento ontológico:

O Ser Mais Perfeito possui todas as perfeições;

a existência é uma perfeição;

logo, o Ser M ais Perfeito existe.

A plicando sua teoria através do esquema argumentativo da ilustração, Russell mostra que ele equivale a:

Existe uma e somente uma entidade $x$ que é a mais perfeita; esta entidade possui todas as perfeições;

a existência é uma perfeição;

logo, esta entidade existe.

O argumento revela-se, assim, uma petição de princípio, pois a conclusão equivale à primeira premissa, que não foi provada ${ }^{35}$.

Na 5a Parte (0 n D enoting, pp. 492-3), que constitui o epílogo, Russell adota um procedimento diferente do tradicional. Ao invés de simplesmente fazer um resumo dos principais resultados obtidos no texto, ele dá dois passos finais. No primeiro, Russell retoma a questão epistemológica col ocada na introdução, explorando uma das conseqüências de sua teoria neste domínio. No segundo, encerra a discussão, tentando convencer o leitor de que ele não deve predispor-se contra a Teoria das Descrições em virtude de sua complexidade, pois esta é inevitável quando a denotação está envolvida. A principal conseqüência filosófica da teoria, que Russell apresenta em seu epílogo, já foi comentada anteriormente e é a seguinte: quando conhecemos alguma

\footnotetext{
${ }^{34}$ Russell, op. cit., 490.

35 Neste ponto, Russell ainda acrescenta: a) uma crítica à posição de McColl sobre as expressões denotativas, que é identificada com a teoria de Meinong; b) uma nova ilustração da utilidade de sua Teoria das Descrições, no que diz respeito ao uso de definições em matemática e à interpretação da identidade. Estes argumentos são menos importantes e simplesmente procuram reforçar as vantagens da teoria de Russell. Por razões de espaço, deixaremos de comentá-los aqui.
} 
coisa por descrição, e não por contato direto, as proposições em que esta coisa é introduzida por meio de uma frase denotativa não contêm real mente esta coisa, mas apenas as funções proposicionais que fazem parte da frase denotativa. Neste caso, conhecemos as propriedades da coisa sem ter contato direto com a própria coisa. Isto é comprovado através do esquema argumentativo baseado na estrutura do real, quePerelman denomina argumento pragmático $0^{36}$. Com efeito, Russell simplesmente procura mostrar aqui uma conseqüência, por ele considerada favorável, da aplicação da Teoria das Descrições. Para convencer o leitor a não se predispor contra a complexidade de sua teoria, Russell recomenda queele tente construir sua própria teoria da denotação. Isto, pensa Russell, convencerá o leitor de que uma teoria da denotação deve ser inevitavelmente complexa, como a que acaba de ser exposta. Aqui também, o filósofo britânico está justificando sua abordagem através do argumento pragmá tico de que a conseqüência desfavorável de qualquer tentativa de se elaborar uma teoria relativa à denotação é a excessiva complexidade.

Passemos agora às técnicas heurísticas de Russell em $0 \mathrm{n}$ D enoting. Por técnicas heurísticas entendemos os procedimentos criativos utilizados pelo autor na elaboração da peça argumentativa que constitui o texto a ser analisado. Estas técnicas podem ser aplicadas em qualquer um dos aspectos envolvidos pela análise argumentativa (estratégia geral, esquemas argumentativos e convergência dos argumentos). Ora, as considerações feitas até agora permitem supor que o grande adversário de Russell em On Denoting não é Meinong, mas Frege. $O$ primeiro oferece uma solução de caráter idealista, que pode ser criticada de diferentes maneiras. Já o segundo oferece uma solução de caráter lógico, que não envolve erro e pode ser acusada, no máximo, de artificialismo. E a importância conferida a Frege em On D enoting é digna de nota. Em virtude disso, podemos dizer que Russell adota a estratégia heurística do anti-modelo com relação a Frege ${ }^{37}$. Deste modo, os procedimentos e

${ }^{36} \mathrm{O}$ argumento pragmático é um esquema argumentativo baseado na estrutura do real que permite apreciar alguma coisa em função de suas conseqüências favoráveis ou desfavoráveis. Cr. Perelman \& Olbrechts-Tyteca, op. cit., tome second, 358-60.

${ }^{37}$ Ao aplicar este conceito, estamos seguindo Plebe \& Emanuele, para os quais a técnica do antimodelo constitui um procedimento para construir criativamente uma argumentação a partir da oposição sistemática a um modelo já dado, estimulando assim a nossa imaginação a partir deste último. A técnica do antimodelo, idealizada por Górgias, apresenta duas alternativas possíveis: a) escrever contra alguém (como faziam os gregos, cujos textos, dentro desta técnica, começavam sempre por Contra... ); b) introduzir uma oposição dialógica dentro de um mesmo escrito (como no caso de Abelardo, que escreveu um texto intitulado Sim e Não). Cfr. A. Plebe \& P. Emanuele, Manual de Retórica, São Paulo: Martins Fontes, 1992, 35-6. Esta noção é muito mais interessante para a análise argumentativa do que a proposta por Perelman \& Olbrechts-Tyteca, que consideram o antimodelo simplesmente como um esquema argumentativo que funda a estrutura do real. Para eles, o antimodelo é um argumento que fundamenta pelo caso particular, como o exemplo, e tem aplicação predominan- 
resultados do pensador austríaco parecem ser heuristicamente invertidos de forma sistemática por Russell, possibilitando uma série de resultados inovadores. Assim, por exemplo, se, em Frege, a proposição contendo uma descrição definida na posi ção de sujeito pressupõe uma proposição afirmando a existência da entidade a que a descrição se refere, em Russell acontece o oposto (a proposição em questão não pressupõe, mas afirma a existência da entidade a que a descrição se refere); se, em Frege, a descrição definida é uma expressão denotativa que não desaparece através da análise, em Russell as coisas são diferentes (a descrição definida não é uma expressão denotativa, mas um signo inautêntico, que desaparece através da análise); se, em Frege, a proposição da linguagem natural que contenha uma descrição vazia na posição de sujeito não é verdadeira nem falsa, desrespeitando a lei do terceiro excluído, em Russell esta lei é obedecida (proposição envolvida possui um valor de verdade definido, sendo simplesmente falsa). Isto permite também o estabelecimento criativo de novas categorias lógicas, como, por exemplo, as provenientes da distinção entre ocorrência primária e secundária da descrição. Novas categorias epistemológicas também são possibilitadas, quando, no conhecimento por descrição, fica claro que conhecemos as propriedades da coisa, mas não a própria coisa. Não devemos esquecer que isto também permite uma nova forma de avaliação lógica do argumento ontológico, agora entendido como uma petição de princípio.

Como último item de nossa análise, vejamos agora a convergência dos argumentos em $0 \mathrm{n}$ D enoting. Através da expressão convergência dos argumentos estamos nos referindo à eficiência da articulação e combinação da estratégia geral de argumentação, das técnicas heurísticas e dos diversos esquemas argumentativos no que diz respeito à demonstração da tese principal do autor ${ }^{38}$. Já sabemos que a linha geral da argumentação de Russell consiste, grosso modo, em apresentar sua teoria e reco-

temente no caso da conduta. Assim, se a referência a um modelo permite promover certas condutas como adequadas, a referência a um antimodelo permite desprestigiar estas condutas como inadequadas. Cfr. Plebe \& OlbrechtsTYTECA, op. cit., tome second, 488-92. Sobre nossa posição a respeito das relações entre as idéias aqui citadas, ver P. R. MARGUTTI, Análise do discurso e argumentação, in: H. MARI ET ALII (eds.), Fundamentos e dimensões da análise do discurso, Belo Horizonte: Núcleo de Análise do Discurso (FALE/UFMG), Carol Borges Editora, 1999, 87-106.

38 Perelman \& Olbrechts-Tyteca utilizam a expressão interação dos argumentos para estudar este importante aspecto da argumentação, reservando o termo convergência para uma situação particular desta interação. Em nossa opinião, eles apenas levantam a questão da interação, sem oferecer um tratamento sistemático efetivo da mesma (Cfr. Perelman \& Olbrechts-Tyteca, op. cit., tome second, $610 \mathrm{ss}$.). Esta é uma das razões pelas quais estamos substituindo interação por convergência. A segunda expressão enfatiza muito mais a articulação geral dos procedimentos argumentativos utilizados para demonstrar a tese principal da peça argumentativa a ser analisada. 
Iher evidências a favor da mesma através da exibição das dificuldades das teorias alternativas e das vantagens da nova teoria na solução destas dificuldades.

A nosso ver, o ponto-chave para se avaliar a convergência da argumentação russelliana em 0 n D enoting está no papel desempenhado pelos lances argumentativos de exibir as dificuldades das teorias de M einong e Frege e mostrar as vantagens da Teoria das Descrições (3a e 4a Partes).

Na discussão das dificuldades das teorias alternativas (3a Parte), sabemos que os autores escolhidos são Meinong e Frege. A razão desta escolha está muito provavelmente no fato de que as teorias de ambos constituem paradigmas das correntes opostas no tratamento das descrições definidas, como já visto no estudo do contexto de $0 \mathrm{n}$ D enoting. Mas Meinong é deixado rapidamente de lado, em virtude da maior importância de Frege. Além disso, Bradley, que também constituiria uma alternativa, não élevado em consideração, talvez por sua postura idealista, já criticada por Russell em outros lugares.

Quanto à argumentação desenvolvida nesta parte, o mínimo que pode ser dito é que a mesma se revela bastante problemática. A crítica da posição de Frege deixa bastante a desejar, por três motivos principais. Em primeiro lugar, Russell acusa Frege de desrespeitar a lei de contradição, ao reconhecer que proposições como o atual rei da França é calvo e o atual rei da França não é calvo não possuem valor de verdade definido. Mas ele se esquece que, para Frege, isto acontece em virtude de uma imperfeição da linguagem natural, que pode e deve ser contornada numa linguagem logicamente correta através do procedimento de se estipular que descrições vácuas designam o conjunto vazio. Em segundo lugar, Russell é obrigado a reconhecer que a solução fregiana de atribuir artificial mente uma referência (conjunto vazio) a uma descrição sem referente não leva a erro lógico efetivo $0^{39}$. O máximo que el e consegue alegar contra Frege é que tal solução émuito artificial. Mas não há como negar que Russell retoricamente ignora o fato de que sua própria solução também é muito artificial. Com efeito, quem imaginaria que enunciar uma proposição simples como 0 atual rei da França é calvo equivaleria a enunciar algo tão esdrúxulo como existe pelo menos uma entidade $x$ tal que $x$ ocupa o trono francês e $x$ é único e x é calvo? Isto também é, certamente, muito artificial. Mas Russell, ao invés de reconhecêlo, prefere dizer eufemisticamente que sua teoria é complexa e, no final de $0 \mathrm{n}$ D enoting, paradoxalmente procura tornar o leitor favorável à sua solução, alegando que a complexidade de uma teoria da denotação é inevitável. Na verdade, este argumento poderia ser dirigido contra o próprio Russell, a favor de Frege, cuja solução, pela via da pressuposição semântica e pelo procedimento de estipular o conjunto vazio como

39 Russell, op. cit., 484. 
significado de uma descrição vácua, é bem mais simples que a de Russell. Em terceiro lugar, a crítica de Russell à distinção fregiana entre sentido e significado é terminologicamente inadequada, obscura e controversa. A inadequação da terminologia já foi comentada: através dela, Russell equipara Sinn a meaning e Bedeutung, a denotation. A conseqüência disto está em que a distinção entre sense e denotation, que estaria mais próxima da distinção fregiana ${ }^{40}$, fica sem explicação. Além disso, os termos sense emeaning parecem ter-setornado equival entes em Russell. Este problema é simplesmente ignorado pelo autor de $0 \mathrm{n}$ D enoting. Quanto à obscuridade e ao aspecto controverso da crítica à distinção entre sentido esignificado, é difícil admitir que a teoria fregiana realmente permita a passagem indevida de 0 significado de [1] (o complexo denotativo em [2]) para [3] (The curfew tolls the knell of parting day) através de [2] (o primeiro verso da 'Elegia' de Gray), se é que Russell realmente pretende isto. Com efeito, cada uma destas expressões possui sentido e significado definidos, não havendo qualquer transição indevida de um para o outro, como se pode ver pelo esquema abaixo:

a) sentido de [1]: o complexo denotativo em [2]; significado de [1]: o primeiro verso da 'Elegia' de Gray;

b) sentido de [2]: o primeiro verso da 'Elegia' de Gray; significado de [2]: The curfew tolls the knell of parting day;

c) sentido de [3]: The curfew tolls the knell of parting day; significado de [3]: inexistente, porque se trata de uma proposição pertencente ao domínio da ficção (com efeito, a linguagem poética não se refere a coisa alguma e [3] não é verdadeira nem falsa.

Como se pode observar, cada uma das expressões acima possui significado próprio e não parece haver qualquer passagem indevida de 0 significado de [1] para [3]. As inúmeras divergências entre os comentadores de Russell simplesmente comprovam a obscuridade de seu argumento e suas intenções. Church, por exemplo, admite que Russell está de fato criticando a distinção fregiana e tenta mostrar que ele está errado. Butler faz o mesmo. Searle argumenta que Russell está de fato refutando a conjunção da distinção fregiana com a sua negação. Geach afirma que Russell confunde a distinção fregiana com sua própria, entre meaning e denotation, tal como apresentada nos Princípios da M atemática. Cassin também pensa que Russell está atacando suas próprias teorias nesta mesma obra, mas que ele está ciente disso. Ayer aceita a crítica russel liana como efetivamente questionando a distinção fregiana, mas simplesmente repete o argumento obscuro de Russell. Dummett pensa que, embora confusa, a argumentação de Russell constitui pelo menos uma crítica válida da distinção fregiana entre sentido

${ }^{40}$ A nosso ver, contudo, a distinção mais próxima de todas seria entre sense (Sinn) e meaning (Bedeutung). 
indir eto e significado $0^{41}$. Blackburn \& Code consideram o argumento uma crítica efetiva da distinção fregiana eo interpretam como provando que um regresso ao infinito é gerado quando se tenta falar a respeito de uma expressão intermediária como [2] $]^{42}$.

Na discussão das vantagens da abordagem de Russell (4a Parte), cabe observar que a Teoria das Descrições também possui al gumas conseqüências indesejáveis que inexplicavelmente não foram discutidas neste lugar. Assim, na argumentação em torno das não-entidades, Russel mostra, contra Meinong e Frege, queo quadrado redondo é redondo possui valor de verdade definido e é uma proposição falsa. Mas, talvez para não enfraquecer sua própria teoria, Russell deixa de reconhecer que a negação desta proposição é verdadeira, na ocorrência secundária de 0 quadrado redondo, e falsa, na ocorrência primária da mesma descrição, como se pode ver pelo esquema que segue:

[A] o quadrado redondo é redondo equivale a $(E x)[x$ é quadrado e redondo $\& x$ é único $\& x$ é redondo]: trata-se de uma proposição FALSA, porque afirma a existência de uma entidade não existente; [B] o quadrado redondo NÃ O é redondo:

[B1] na interpretação com a descrição em ocorrência primária, equivale a $(E x)[x$ é quadrado e redondo $\& x$ é único $\&$ x N ÃO é redondo]: trata-se de uma proposição FALSA, porque afirma a existência de uma entidade não existente;

[B2] na interpretação com a descrição em ocorrência secundária, equivale a NÃO (Ex) [x é quadrado e redondo \& $x$ é único $\& x$ é

${ }^{41}$ Todo signo, segundo Frege, possui sentido costumeiro e sentido indireto, além de significado costumeiro e significado indireto. O sentido indireto ocorre no discurso indireto, quando se fala do sentido das palavras de outrem. O significado indireto de um signo é seu sentido costumeiro.Assim, em Galileu acreditava que a terra gira em torno do sol, o que está em jogo é o significado indireto de a terra gira em torno do sol, ou seja, o seu sentido costumeiro. Se estivesse em jogo o seu significado costumeiro (um valor de verdade; no caso, o verdadeiro), então qualquer expressão com o mesmo significado, como, por exemplo, Reagan tem rugas (que também é verdadeira), poderia substituir a terra gira em torno do sol. Ora, todos sabemos que a sentença Galileu acreditava que Reagan tem rugas é, no mínimo, falsa. Cfr. G. FreGe, Lógica e Filosofia da Linguagem, (trad. P. Alcoforado), São Paulo: Cultrix/EDUSP, 1978, 64.

42 Para o acompanhamento deste debate, cfr. A. CHURCH, Carnap's Introduction to Semantics, Philosophical Review 52 (1943) 302; R. J. ButLer, The Scaffolding of Russell's Theory of Descriptions, Philosophical Review 63 (1954) 362-3; J . R. SeARLE, Russell's Objections to Frege's Theory of Sense and Reference, Analysis 18 (1958) 143; P. T. GeACH, Russell on meaning and denoting, Analysis 19 (1950) 69; 72; C. E. CASSIN, Russell's Discussion of Meaning and Denotation: a Reexamination, in: E. D. Klemke (ed.). Essays on B. Russell, Illinois: Un. of Illinois Press, 1970, 256-72; A. J. Ayer, Russell and Moore. The Analytical Heritage, London and Basingstoke: Macmillan, 1971; M. Dummett, Frege: Philosophy of Language, London: Duckworth, 1981, 267-8; S. Blackburn \& A. Code, The Power of Russell's Criticism of Frege: On Denoting pp. 48-58, Analysis 37 (1978) 65-77. 
redon do]: trata-se de uma proposição VERDADEIRA, pois afirma a inexistência de uma entidade não existente.

Como se pode ver, [A ] e[B1], embora contraditórias, desrespeitam a lei de contradição, pois são fal sas ao mesmo tempo. Ora, isto certamente não constitui uma vantagem da Teoria das Descrições, em comparação com as teorias alternativas. Quanto a [A ] e [B2], é verdade que, pelo menos neste caso, a lei de contradição fica confirmada, pois estas proposições possuem valores de verdade diferentes. Mas estes valores são contraintuitivos, uma vez que ninguém esperaria que o quadrado redondo é redondo fosse fal sa e o quadrado redondo não é redondo fosse verdadeira. Isto não parece nos deixar em melhor situação do que estaríamos no caso de Meinong ou de Frege. Desse modo, Russell não parece ter cumprido inteira ou adequadamente a promessa feita à página 482 de $0 \mathrm{n}$ D enoting, quando nos diz que sua teoria não é contrária à lei de contradição. É digno de nota que estes aspectos desfavoráveis da Teoria das Descrições tenham sido completamente ignorados por Russell.

Com base nestas considerações, podemos dizer que, no que diz respeito à disposição geral dos argumentos em On D enoting, Russell parece adotar a ordem nestoriana, na qual a parte mais fraca fica no centro, devidamente protegida pelos flancos mais fortes. Assim, a confirmatio russelliana é estruturada de modo tal que as dificuldades das teorias alternativas (altercatio), que incluem a controversa crítica de Frege, são colocadas na parte média do texto, sendo precedidas pela apresentação da nova teoria (propositio) e seguidas pela discussão das vantagens da nova teoria (argumentatio). O caráter técnico da nova teoria e seus surpreendentes resultados, quando se escamoteiam as conseqüências desfavoráveis, oferecem uma força argumentativa capaz de compensar as deficiências da crítica a Frege. Esta confirmatio está, por sua vez, ladeada por uma introdução e um epílogo, que mostram o caráter epistemologicamente importante da questão e da solução proposta. Não devemos esquecer também o reforço argumentativo feito através do apelo dramático no último parágrafo do epílogo, para que o leitor não se coloque contra a Teoria das Descrições antes de tentar, ele próprio, resolver o problema da denotação e constatar a necessidade de uma solução complexa como a de Russell. Há um aspecto anedótico importante que ilustra muito bem as dificuldades da argumentação russelliana a favor de sua teoria: conta-se que o editor da revista $M$ ind, ao receber o manuscrito de $0 \mathrm{n}$ D enoting, considera a teoria ali exposta tão esdrúxula que pede a Russell para reconsiderar a publicação naqueles termos. Nosso filósofo, contudo, está tão convencido da correção da teoria que insiste na publicação.

Para terminar, cabe tentar responder, ainda que rapidamente, a uma pergunta que o leitor já deve estar fazendo a si próprio: até que ponto está Russell consciente dos procedimentos argumentativos usados em On D enoting? Embora não seja possível demonstrar que todos os problemas e respectivas soluções argumentativas aqui considerados te- 
nham sido conscientemente adotados por Russell, duas coisas são certas. Primeiro, que um autor como ele, em geral brilhante na defesa de suas idéias, dificilmente iria adotar procedimentos argumentativos pelos quais não tivesse optado de maneira lúcida e consciente. Segundo, que os procedimentos em questão se encontram efetivamente presentes em $0 \mathrm{n}$ D enoting e todos contribuem para reforçar a argumentação de Russell a favor de sua teoria. Seria muita coincidência se todos os procedimentos adotados fossem capazes de convergir tão eficientemente na defesa da Teoria das Descrições apenas pela força do acaso.

\section{$V$ - Conclusões}

A aplicação do método de análise argumentativa ao texto de $0 \mathrm{n}$ D enoting mostra que o mesmo se enquadra no espírito russelliano de resolver problemas filosóficos através de procedimentos lógicos. Através da contextualização da obra analisada, vemos que, antes de escrevêla, Russell se encontra envolvido com o problema das frases denotativas e procura resolver um impasse criado por dois grupos de soluções alternativas. O primeiro grupo éformado por Brentano, Meinong, Moore e o próprio Russell dos Princípios da M atemática. Sua solução preserva a objetividade, mas pagando o elevado preço de postular um excesso de entidades e desrespeitar a bivalência. O segundo grupo tem em comum a desconfiança com respeito à forma gramatical da proposição, que oculta sua verdadeira forma lógica. Este grupo é formado por Bradley, que preserva a objetividade, mas paga o preço de uma solução altamente idealista, e por Frege, que também preserva a objetividade, mas desrespeita a bivalência e adota a solução bastante artificial do conjunto vazio para recuperá-la. Russell aceita este problema, e sua solução pretende superar todas estas dificuldades. Ele se propõe a elaborar uma teoria realista que preserve a bivalência e descubra a verdadeira forma lógica das proposições envolvidas, sem recorrer a procedimentos muito artificiais. Esta contextual ização fornece o panorama do ponto de partida de Russell em On D enoting e mostra o tipo de auditório a que ele pretende se dirigir: são pensadores da comunidade filosófica que se interessam pela questão e cujos exemplos seriam Meinong, Moore, Bradley, Frege etc.

A apresentação da Teoria das Descrições nos revela até que ponto Russell é bem sucedido em sua empreitada. De acordo com a teoria, as descrições definidas em posição de sujeito surgem como expressões denotativas inautênticas, ou seja, expressões que, embora possuam uma forma gramatical definida, desaparecem inteiramente através da análise, que revela sua verdadeira forma lógica. Isto envolve as seguintes conseqüências lógicas: a) a afirmação de existência da entidade a que a descrição se refere não é pressuposta, mas faz parte da afirmação; b) 
a descrição definida dá lugar, na análise final, a uma articulação de pelo menos três funções proposicionais, das quais uma fixa a propriedade básica da entidade descrita, outra estabelece sua unicidade, e outra atribui um predicado a esta entidade; c) a negação de uma proposição contendo uma descrição definida na posição de sujeito é ambígua, pois sua forma lógica nos mostra que ela pode ocupar duas posições diferentes. A principal conseqüência filosófica da teoria está em que as coisas conhecidas por descrição não são conhecidas em si mesmas, mas através de suas propriedades. O somatório destas conseqüências deixa daro que Russell não consegue evitar para sua teoria a desvantagem do artificialismo, disfarçada sob o nome de complexidade.

Partindo da relevância do problema da denotação, a estratégia argumentativa adotada por Russell em $0 \mathrm{n}$ D enoting consiste na tentativa de mostrar que sua teoria, apesar de complexa, éa mais adequada, porque as teorias alternativas enfrentam dificuldades que ela resolve satisfatoriamente, e porque qual quer outra teoria sobre a denotação deverá ser complexa. Daí a divisão de On Denoting em cinco partes. Nestas, a 1a (introdução) e a $5^{a}$ (epílogo) estão ligadas pela discussão de aspectos do problema filosófico da denotação; a 2 a envolve a apresentação técnica da teoria de Russell; a 3a corresponde à crítica das teorias adversárias e, finalmente, a $4^{a}$ expõe as vantagens da teoria proposta.

Para implementar sua estratégia, Russell utiliza uma série de esquemas argumentativos que podem ser encontrados na classificação de Perelman. Dentre eles, destacam-se os seguintes: identidade, dissociação de noções, ilustração, exemplo, contradição e argumento pragmático.

Tudo indica que o procedimento heurístico básico de Russell é o do anti-modelo com relação a Frege, cuja teoria recebe maior atenção em 0 n D enoting. Este procedimento heurístico permite a obtenção de uma série de resultados originais por oposição a Frege, como, por exemplo: a) a existência da entidade descrita é afirmada e não pressuposta; b) a negação é ambígua na linguagem natural; c) a descrição definida não é um nome próprio; d) a proposição contendo uma descrição vazia é simplesmente falsa etc. Novas dissociações são também obtidas ou reforçadas, como, por exemplo: a) ocorrência primária e secundária; b) forma gramatical e forma lógica; c) conhecimento por descrição e conhecimento por contato direto. Não devemos esquecer também a nova avaliação do argumento ontológico, agora identificado como uma petição de princípio.

$\mathrm{Na}$ avaliação da convergência dos argumentos em $0 \mathrm{n}$ D enoting, fica claro que o ponto mais fraco da argumentação russelliana está na crítica à posição de Frege, que é reconhecida como logicamente correta, embora artificial. Inegavelmente, a Teoria das Descrições também possui tais atributos. Em virtude disso, Russell adota a ordem nestoriana para distribuir seus argumentos, deixando a parte mais fraca da crítica a Frege na parte média do seu texto. Outras táticas de caráter predominantemente retórico são também utilizadas, como, por exemplo, a ênfase 
nas conseqüências favoráveis da Teoria das Descrições e o escamoteamento das suas conseqüências desfavoráveis. Ao final, Russell faz um apelo dramático ao leitor, para defender a complexidadede sua teoria, mas com isto está também reforçando a teoria deFrege, já que, conformeobservado, complexidade pode ser tomada aqui como sinônimo de artificialismo. E é bastante plausível supor que Russell adota conscientemente a maior parte dos procedimentos argumentativos encontrados em seu texto.

De um modo geral, a presente aval iação mostra que a argumentação de Russell envolve o apelo a recursos de caráter eminentemente retórico e não consegue derrubar com eficácia a principal teoria adversária, representada por Frege. O máximo que se pode dizer é que Russell consegue apenas sugerir, de maneira não coercitiva, uma teoria alternativa, tão artificial quanto (ou mais do que) a fregiana, e com resultados igualmente impalatáveis. A pesar do sucesso inicial na divulgação da teoria, não é à toa que Strawson, quarenta e cinco anos após a publicação de On D enoting, consegue reabrir a discussão contra Russell, ao defender uma posição de tipo fregiano na questão do estatuto referencial das descrições definidas em posição de sujeito ${ }^{43}$.

Em conexão com resultados obtidos em outras ocasiões, o presente trabalho permite concluir que o método proposto para a análise argumentativa pode ser aplicado a casos radical mente diferentes. Como já foi dito, este método já foi aplicado com sucesso a dois casos considerados argumentativamente "anômalos", representados pela análise de A origem da tragédia, de Nietzsche, e do Tractatus Logico-P hilosophicus, de Wittgenstein ${ }^{44}$. Sua aplicação a um caso "não anômalo", de tipo socrático, em que predomina a argumentação lógica, como acontece com 0 n D enoting, mostra que o método possui flexibilidade suficiente para enfrentar situações bastante diferentes umas das outras. E a análise surpreendentemente revela que um texto tão voltado para o simbolismo lógico e tão técnico como o russelliano procura esconder suas fal has através dos procedimentos argumentativos caracterizadas pela Nova Retórica de Perelman \& Olbrechts-Tyteca.

\section{Referências bibliográficas}

AYER, A. J. Russell and M oore. The A nalytical H eritage. London and Basingstoke: Macmillan, 1971.

BLACKBURN, S. \& CODE, A. The power of Russell's criticism of Frege: $0 \mathrm{n}$ Denoting pp. 48-58. A nalysis 37 (1978) 65-77.

BRENTANO, F. Psychologie du point de vue empirique. Trad. M. de Gandillac. Paris: Aubier, 1944.

${ }^{43}$ Cfr. P. F. Strawson, On Referring, Mind 59 (1950) 320-44.

44 Ver notas 1-3 do presente texto. 
BUTLER, R. J. The scaffolding of Russell's theory of descriptions. Philosophical Review 63 (1954) 350-64.

CASSIN, C. E. Russell's discussion of meaning and denotation: a reexamination. In: KLEMKE, E. D. (ed.). Essays on B. Russell. Illinois: Un. of Illinois Press, 1970, 256-72.

CHURCH, A. Carnap's introduction to semantics. Philosophical Review 52 (1943) 298-304.

DUMMETT, M. Frege: Philosophy of Language. London: Duckworth, 1981.

EDWARDS, P. (ed. in chief) Encyclopaedia of Philosophy. N. York: The MacMillan Co \& the Free Press; London: Collier-MacMillan Ltd., 1967.

FREGE, G. Lógica e Filosofia da Linguagem. Sel., intr., trad. e notas de P. Alcoforado. São Paulo: Cultrix/ EDUSP, 1978.

GEACH, P. T. Russell on meaning and denoting. A nalysis 19 (1950) 69-72.

MOORE, G. E. The Nature of Judgment. In: BALDWIN, Th. (ed.). G. E. M oore: Selected W ritings. London and N. York: Routledge, 1993, 1-19.

PASSMORE, J. A Hundred Y ears Philosophy. Harmondsworth, Middlesex, England: Penguin Books Ltd., 1980.

PERELMAN, Ch. \& OBRECHTS-TYTECA, L. Traité de I'A rgumentation. Paris: PUF, 1958, 2 vols.

PINTO, P. R. Margutti. Nietzsche, a filosofia e a retórica: uma análise de $A$ O rigem da Tragédia enquanto forma de argumentação. Kriterion vol. XXXV, no 89 (1994) 45-73.

Loyola, 1998.

. Iniciação ao silêncio. U ma análise argumentativa do Tractatus. São Paulo:

PLEBE, A. \& EMANUELE, P. M anual de Retórica. São Paulo: Martins Fontes, 1992.

RUSSELL, B. The Principles of M athematics. London: Allen \& Unwin Ltd., 1903. . On Denoting. M ind vol. 14 (1905) 479-93.

. M eu pensamento filosófico. Trad. de B. Silveira. São Paulo: Cia Editora

Nacional, 1960.

SEARLE, J. R. Russell's objections to Frege's theory of sense and reference. A nalysis 18 (1958) 137-43.

STRAWSON, P. F. On Referring. M ind 59 (1950) 320-44.

WRIGHT, C. Frege's Conception of Numbers as Objects. A berdeen: Aberdeen Un. Press, 1983.

Endereço do Autor:

Av. Antônio Carlos, 6627

30270-901- MG 